\title{
New advice on feeding and weaning babies to reduce tooth decay risk
}

A position statement on infant feeding has been produced by the British Society of Paediatric Dentistry (BSPD). The aim of the statement is to provide evidence-based recommendations to support all health practitioners who advise parents on feeding and weaning their babies.

The BSPD position statement examines the evidence on both bottle and breast feeding. The evidence in favour of stopping bottlefeeding by the age of one has been strong

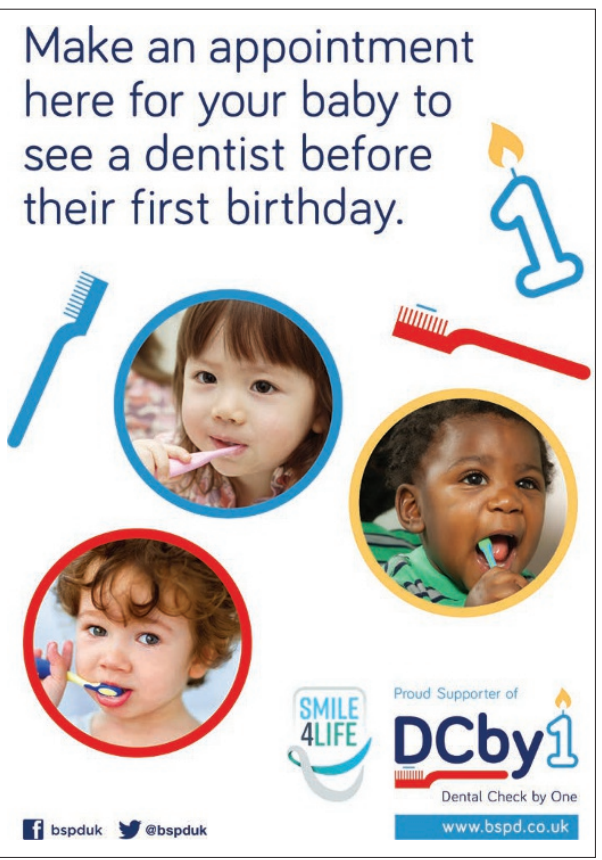

for some time but there has been no clear evidence around breastfeeding and dental health. However, new research ${ }^{1}$ published in 2017 found a higher risk of dental caries if breastfeeding continues on demand and through the night after the age of 12 months.

President of BSPD Claire Stevens said:

'There is an emerging evidence-base that suggests that when a baby is breast fed on demand and through the night after 12 months of age following the introduction of solid foods, there is a potential link with dental decay.
'The age of one is an important milestone. Parents who are bottle-feeding are strongly advised to withdraw the bottle by this time and mothers who are breastfeeding may wish to consider reducing night-time feeds. Those who choose to continue breastfeeding should get preventative advice from their dentist so the baby has a low sugar diet and its teeth are regularly brushed with a fluoride toothpaste. Ideally, the last thing on a child's teeth at bedtime should always be fluoride toothpaste.

'By publishing clear recommendations supported by the best available evidence, we hope that healthcare professionals can advise and support parents sensitively on the steps to take to prevent dental decay in first teeth. Our statement is aimed at doctors, dentists, health visitors and practice and district nurses.'

Key recommendations arising out of the position statement include:

- Only milk or water is placed in a baby's bottle

- From six months an open-topped or free-flow cup should be introduced

- Children should receive their first dental check by the age of one - Dental Check by One (\#DCby1)

- Thereafter, the child should be seen once a year or more, depending on the advice of your dentist

- Habits such as dummy use and digit sucking should be withdrawn by 12 months.

Healthcare professionals can find the position statement on infant feeding at: http://bspd.co.uk/Resources/

Position-Statements.

1. Peres K G, Nascimento G G, Peres M A et al. Impact of prolonged breastfeeding on dental caries: a population-based birth cohort study. Pediatrics 2017; 140: 20162943.

A free poster promoting Dental Check by One is now available on the BSPD website (pictured here): http:// bspd.co.uk/Resources/Dental-Check-by-One.

\section{Notice of death}

It is with sadness that we report the recent death of Ronald Walter, aged 92, who was well known in the profession as the owner, for many years, of a dental laboratory in Wigmore Street, London. 